\title{
Novel HLA Class I Alleles Associated with Indian Leprosy Patients
}

\author{
U. Shankarkumar,* K. Ghosh, S. Badakere, and D. Mohanty \\ HLA Department, Institute of Immunohaematology (ICMR), 13th Floor, KEM Hospital, \\ Parel, Mumbai-400012, Maharastra, India
}

Received 19 October 2002; revised 23 November 2002; accepted 6 December 2002

\begin{abstract}
Convincing results on HLA Class II associations have been reported, however data on HLA class I association are limited and inconsistent from studies in Leprosy. We present here the HLA A, B, and C allele distribution by molecular high resolution PCRSSOP technique in 32 leprosy patients compared with the 67 controls, from the same ethnic background. The significant results from the present study were a significant increase in frequency of HLA A*0206, A*1102, B*4016, B*5110, Cw*0407, and Cw*0703 was observed when compared to controls. A striking decrease in the frequency of HLA A*0101, Cw*04011, and Cw*0602 leprosy patients was observed when compared to the controls. Further haplotype $\mathrm{A}^{*} 1102-\mathrm{B}^{*} 4006-\mathrm{Cw}^{*} 1502$ was significantly increased among the lepromatous leprosy patients when compared to the controls. It seems that HLA class I alleles play vital roles in disease association/pathogenesis with leprosy among Indians.
\end{abstract}

\section{INTRODUCTION}

Genetic predisposition to both disease susceptibility and host immune response has been postulated. Leprosy disease burden currently is concentrated mainly in six endemic countries; India, Brazil, Myanmar, Madagascar, Nepal, and Mozambique [1]. In India, about 64\% of leprosy prevalence and $78 \%$ of new case detection of the worlds estimated 719330 cases occur [1]. Studies on Humans have suggested that host genetics is important in disease pathogenesis and protection [2]. With the elucidation of genetics and structure of major histocompatibility complex (MHC), T-cell receptor (TCR), and peptide binding, the role of immune response (Ir) genes and TCR in immune response are generally accepted to be important in active adaptive immunity [3] The MHC restriction phenomenon has been explained at the "consensus motif" level [4]. India is known for her endogamous, ethnically distinct caste groups, characterized by unique MHC haplotypes [5, 6]. Leprosy is a chronic infectious disease caused by $M$. leprae, which manifest as a clinical, pathological, and immunological spectrum with paucibacillary tuberculoid leprosy (TT) at one pole and the multibacillary disseminated lepromatous leprosy (LL) at the other extreme [7]. Epidemiological studies suggest that only a small percentage of people exposed to $M$. leprae get the disease, the majority are resistant and develop effective immunity which arrests the growth of the bacteria at a subclinical stage [8]. Since the first studies in 1848 by Daulelson and Beck, many investigators have attempted to establish a genetic factor that would explain the familial spread of the disease [9].
Studies from India have revealed the HLA-DR2 antigen associations in leprosy patients [10] whereas class I studies are limited. Earlier study from Mumbai in 1982 has shown HLA-B40 association in lepromatous leprosy patients [11]. The present study was undertaken in order to reveal the molecular subtype of the associations.

\section{MATERIALS AND METHODS}

\section{Patients and controls}

Thirty-two leprosy patients attending the dermatology clinic, in various hospitals in Mumbai, Maharastra, were studied for HLA A, B, and C alleles and compared with 67 unrelated healthy normal controls from the same endemic region. All the patients included in the study were HIV negative and were being treated with chemotherapy. The controls did not show any clinical symptoms of leprosy. The mean age of the controls was 40 years.

\section{HLA typing}

Genomic DNA was extracted by sodium acetate method [12] from $5 \mathrm{ml}$ of EDTA blood. These Genomic DNA were genotyped for their A, B, and C allele subtypes by polymerase chain reaction reverse line strip sequence-specific oligonucleotide hybridization (PCRRLS-SSOP) strips (Roche Molecular, Oakland, Calif, USA) [13]. Each strip for HLA A typing carried a total of 57 immobilized sequence-specific oligos (SSOs), while the B carried a total of 84 immobilized SSOs. Genomic DNA was amplified using HLA A or HLA B locus 
TABLE 1. High risk HLA class I allele subtypes among the leprosy patients, Mumbai, India.

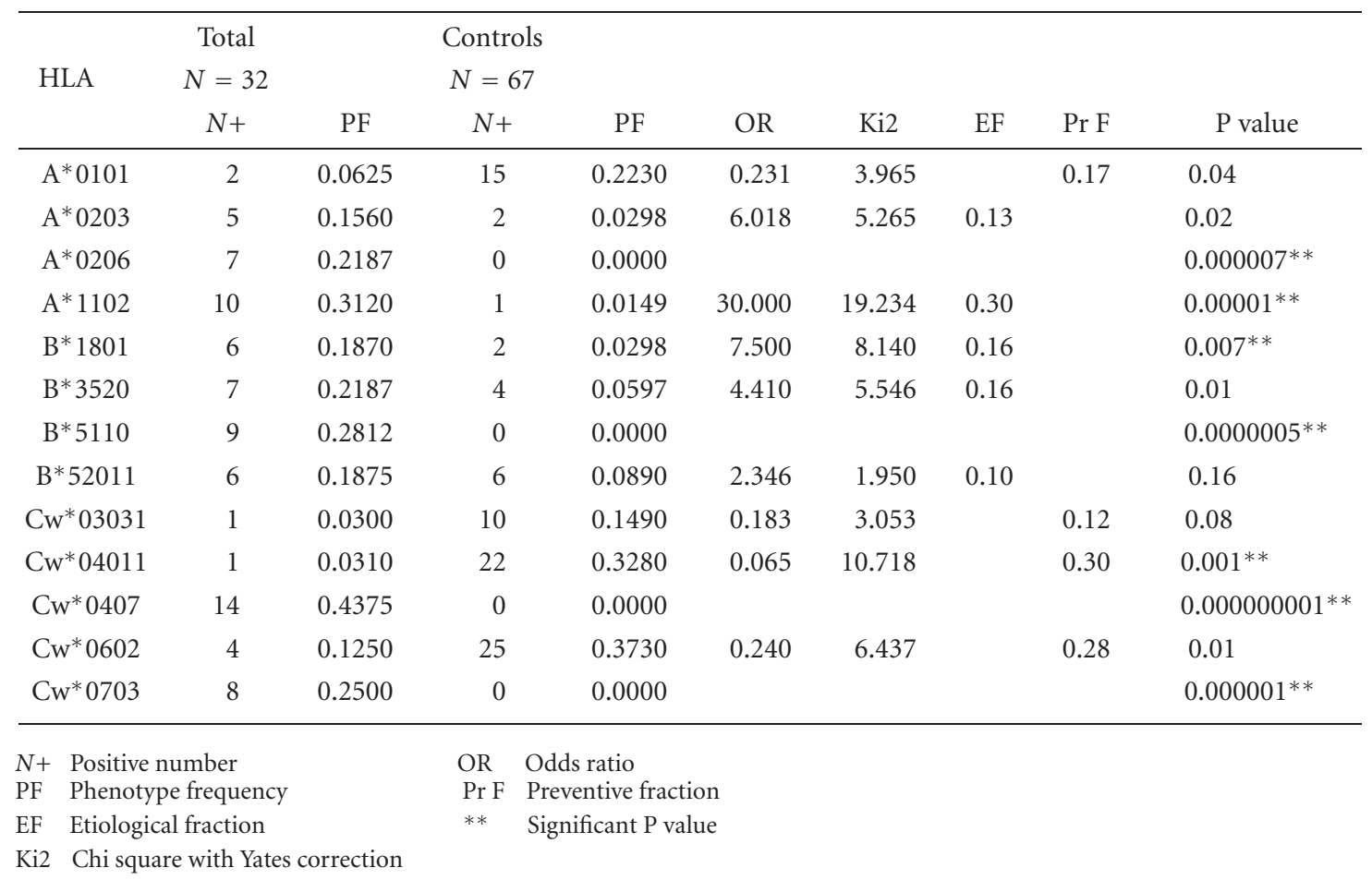

specific biotinylated primers and hybridized with the SSO strips. Streptavidin-conjugated alkaline phosphatase was used as a conjugate for positive color development using bromochloroindolyl phosphate/nitrobluetetrazolium (BICP/NBT) in dimethylformamide (DMF) as a substrate. The alleles were determined using the pattern interpretation software supplied along with the kit.

\section{Statistical analysis}

The phenotype frequencies, odds ratio, probability value, chi square with Yates correction, and aetiological and preventive fraction were estimated using our database and computer programs as described earlier [14]. Since each individual is tested for several HLA alleles and the same data used for comparing the frequency; it is possible that one of the alleles will by chance deviate significantly. To overcome this error, the $\mathrm{P}$ value is corrected by the use of Bonferroni inequality method [15], that is, by multiplying it with the number of alleles compared.

\section{RESULTS AND DISCUSSION}

Some significant findings can be concluded from this study. (1) HLA A*0101, Cw*04011, and $\mathrm{Cw}^{*} 0602$ subtypes were found to be negatively associated with leprosy patients, when compared with controls (Table 1). (2) A*0206, A*1102, B*4016, B*5110, $\mathrm{Cw}^{*} 0407$, and $\mathrm{Cw}^{*} 0703$ alleles were associated with the leprosy patients when compared to controls. (Table 1). (3) Haplotype $A^{*} 1102-B^{*} 4006-\mathrm{Cw}^{*} 1502$ was found to be associ- ated with lepromatous leprosy patients significantly when compared to controls. Various epidemiological studies in the past have suggested that in prolonged contact with lepromatous leprosy patients only less than $2 \%$ of the contact develops Lepromatous leprosy. In the present study, A* $1102-\mathrm{B}^{*} 4006-\mathrm{Cw}^{*} 1502$ is correlated positively and strongly with lepromatous leprosy, and this haplotype constitutes less than $3 \%$ of the control population as expected. Further DRB1 gene typing by PCRSSP typing revealed that $83 \%$ of these haplotypes were found to posses $\mathrm{DRB} 1^{*} 1501$ allele. Some of these associations and protection have not been previously described in the leprosy patients studied from India. HLA $A^{*} 1102, B^{*} 1801$, and $B^{*} 3520$ were significantly increased when compared to the controls. It was interesting to note that $\mathrm{A}^{*} 2413, \mathrm{~B}^{*} 0706, \mathrm{~B}^{*} 4016, \mathrm{Cw}^{*} 0708$, and $\mathrm{Cw}^{*} 1505$ were significantly associated with the lepromatous leprosy patients while they were not associated with tuberculoid type of leprosy when compared to controls. HLA $\mathrm{B} * 5110, \mathrm{Cw}^{*} 0407$, and $\mathrm{Cw}^{*} 0703$ were significantly associated with leprosy patients while $A^{*} 0206$ was significantly associated with the tuberculoid leprosy patients when compared to the controls. The significant haplotypes associated with the leprosy patients when compared to the controls revealed that $\mathrm{A}^{*} 1102-\mathrm{B}^{*} 4006-\mathrm{Cw}^{*} 1502$ was the significant haplotype associated with lepromatous leprosy (Table 2). Further haplotypes A*1102-B*4006$\mathrm{Cw}^{*} 0407$ and $\mathrm{A}^{*} 0203-\mathrm{B}^{*} 4016-\mathrm{Cw}^{*} 0703$ were increased among both the lepromatous and tuberculoid type of leprosy patients when compared to controls. 
Table 2. Two Significant haplotypes associated with the leprosy patients, Mumbai, India.

\begin{tabular}{|c|c|c|c|c|c|c|c|}
\hline \multirow[t]{2}{*}{ Haplotype } & \multicolumn{7}{|c|}{ Percentage frequency } \\
\hline & Control & LL type & OR & $\mathrm{P}$ value & BT type & OR & $\mathrm{P}$ value \\
\hline & $N=67$ & $N=16$ & & & $N=16$ & & \\
\hline$A^{*} 11-B^{*} 40$ & 7.46 & 50.00 & 12.40 & $0.0001^{* *}$ & 12.50 & 1.770 & 0.514 \\
\hline $\mathrm{A}^{*} 1102-\mathrm{B}^{*} 4006-\mathrm{Cw}^{*} 1502$ & 2.98 & 31.25 & 12.51 & $0.000025^{* *}$ & 0.00 & 0.000 & 0.000 \\
\hline$A^{*} 1102-B^{*} 4006-C w^{*} 0407$ & 1.49 & 12.50 & 9.44 & $0.0037^{* *}$ & 6.25 & 4.400 & 0.264 \\
\hline $\mathrm{A}^{*} 02-\mathrm{B}^{*} 40$ & 20.89 & 31.25 & 1.72 & 0.375 & 18.75 & 0.873 & 0.514 \\
\hline $\mathrm{A}^{*} 0203-\mathrm{B}^{*} 4016-\mathrm{Cw}^{*} 0703$ & 1.49 & 12.50 & 9.43 & 0.034 & 6.25 & 4.400 & 0.264 \\
\hline
\end{tabular}

OR Odds ratio

** Significant $\mathrm{P}$ value

Differences in disease susceptibility can be seen at the level of individuals and populations. Genetic epidemiology data indicates that there might be major susceptibility genes that account for a significant proportion of genetic contribution to disease susceptibility. HLA loci evolve very fast, probably as a result of selective pressure from pathogens, and polymorphism in these loci has been associated with altered susceptibility to infectious diseases [16]. Nevertheless, convincing results have been obtained from studies on HLA class II associations with leprosy [10], however, data on HLA Class I associations is limited and inconsistent. In leprosy patients from Iran, HLA B35 was increased, while A1 was decreased in lepromatous leprosy patients [17]. Leprosy patients from Thailand showed HLA B18 and B40 associations in lepromatous leprosy [18]. Haplotypes A2-B40, A11-B40, and A24-B40 were frequent among South Indian leprosy patients [19]. HLA B40 was significantly associated with Mumbai lepromatous leprosy patients [11]. HLA A11 and A33 were increased among Korean leprosy patients [20]. HLA A11 was significantly increased with erythema nodosum leprosum (ENL) leprosy patients from North India [21]. Lepromatous Leprosy patients from North India showed increased frequencies of HLA B60, DR2, DR8, and DQw1 [22]. Increased frequencies of HLA A2, A11, B40, and DR2 were observed among the leprosy patients from South India [23]. Recently, HLA A9, A10, A32, B5, B21, Bw4, Bw6, Cw1, and Cw2 were found to be significantly more frequent among Turkish leprosy patients [24]. In all these earlier studies, the HLA were determined by conventional techniques that might have resulted in a lower resolution of HLA types. The development of DNA-based HLA typing methods has improved the validity of HLA typing. We have employed the high resolution PCR-RLS-SSOP typing to define the HLA class I alleles among the Mumbai leprosy patients. Hence, we have identified novel alleles associated with Mumbai leprosy patients.

\section{REFERENCES}

[1] WHO. Leprosy. global situation. Wkly Epidemiol Rec. 2002;77(1):1-8.

[2] Hill AV. The immunogenetics of human infectious diseases. Annu Rev Immunol. 1998;16:593-617.

[3] Ward ES, Qadri A. Biophysical and structural studies of TCRs and ligands: implications for T cell signaling. Curr Opin Immunol. 1997;9(1):97-106.

[4] Zinkernagel RM, Doherty PC. The discovery of MHC restriction. Immunol Today. 1997;18(1):1417.

[5] Shankarkumar U, Ghosh K, Mohanty D. Defining the allelic variants of HLA A19 in the western indian population. Hum Immunol. 2002;63(9):779-782.

[6] Shankarkumar U, Ghosh K, Colah RB, Gorakshakar AC, Gupte SC, Mohanty D. HLA antigen distribution in selected caste groups from Mumbai, Maharastra, India. J Hum Ecol. 2002;13:209-215.

[7] Ridley DS, Jopling WH. Classification of leprosy according to immunity. a five-group system. Int J Lepr Other Mycobact Dis. 1966;34(3):255-273.

[8] Kaplan G, Cohen ZA. Regulation of cell-mediated immunity in lepromatous leprosy. Lep Rev. 1986;57: 199-202.

[9] Cem Mat M, Yazici H, Ozbakir F, Tuzun Y. The HLA association of lepromatous leprosy and borderline lepromatous leprosy in Turkey. A preliminary study. Int J Dermatol. 1988;27(4):246-247.

[10] Meyer CG, May J, Stark K. Human leukocyte antigens in tuberculosis and leprosy. Trends Microbiol. 1998;6(4):148-154.

[11] Bale UM, Mehta MM, Contractor NM, Bhatia HM, Koticha KK. HLA antigens in leprosy patients. Tissue Antigens. 1982;20(2):141-143.

[12] Miller SA, Dykes DD, Polesky HF. A simple salting out procedure for extracting DNA from human nucleated cells. Nucleic Acids Res. 1988;16(3):1215. 
[13] Mack SJ, Geyer LN, Erlich HA. HLA class I reverse lineblot typing protocol Chapter 3. In IHWG Technical Manual Genomic Analysis of the Human MHC: DNA-Based Typing for HLA Alleles and Linked Polymorphisms. Tilanus MGJ, Hansen JH, and Hurley CKF, Ed. Seattle, Wash: 13th IHWG Publications, Hutchinson Cancer Research Centre; 2000.

[14] Shankarkumar U, Devraj JP, Ghosh K, Mohanty D. Seronegative spondarthritis and human leucocyte antigen association. Br J Biomed Sci. 2002;59(1):3841.

[15] Dunn OJ. Multiple comparisons among means. J Am Statist Assoc. 1961;56:52-56.

[16] Cooke GS, Hill AV. Genetics of susceptibility to human infectious disease. Nat Rev Genet. 2001;2(12):967-977.

[17] Mohagheghpour N, Tabatabai H, Mohammad K, Ramanujam K, Modabber FZ. Histocompatibility antigens in patients with leprosy from Azarbaijan, Iran. Int J Lepr Other Mycobact Dis. 1979;47(4):597600.

[18] Chiewsilp P, Athkambhira S, Chirachariyavej T, Bhamarapravati N, Entwistle C. The HLA antigens and leprosy in Thailand. Tissue Antigens. 1979;13(3):186-188.

[19] Wolf E, Fine PE, Pritchard J, et al. HLA-A, B and C antigens in south indian families with leprosy. Tissue Antigens. 1980;15(5):436-446.

[20] Kim SJ, Choi IH, Dahlberg S, Nisperos B, Kim JD, Hansen JA. HLA and leprosy in koreans. Tissue Antigens. 1987;29(3):146-153.

[21] Agrewala JN, Ghei SK, Sudhakar KS, Girdhar BK, Sengupta U. HLA antigens and erythema nodosum leprosum (ENL). Tissue Antigens. 1989;33(4):486487.

[22] Rani R, Zaheer SA, Mukherjee R. Do human leukocyte antigens have a role to play in differential manifestation of multibacillary leprosy: a study on multibacillary leprosy patients from North India. Tissue Antigens. 1992;40(3):124-127.

[23] Shankarkumar U. Studies on the immunogenetic basis of selected diseases in South India. [Ph.D. thesis]. Madurai: Maduarai Kamaraj University;1994.

[24] Kocak M, Balci M, Pence B, Kundakci N. Associations between human leukocyte antigens and leprosy in the Turkish population. Clin Exp Dermatol. 2002;27(3):235-239.

\footnotetext{
* Corresponding author. E-mail: director@iihicmr .org Fax: +91 224138521
} 


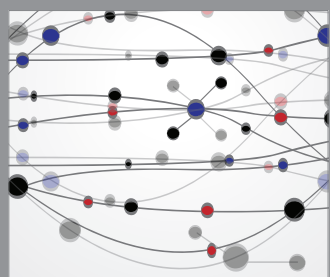

The Scientific World Journal
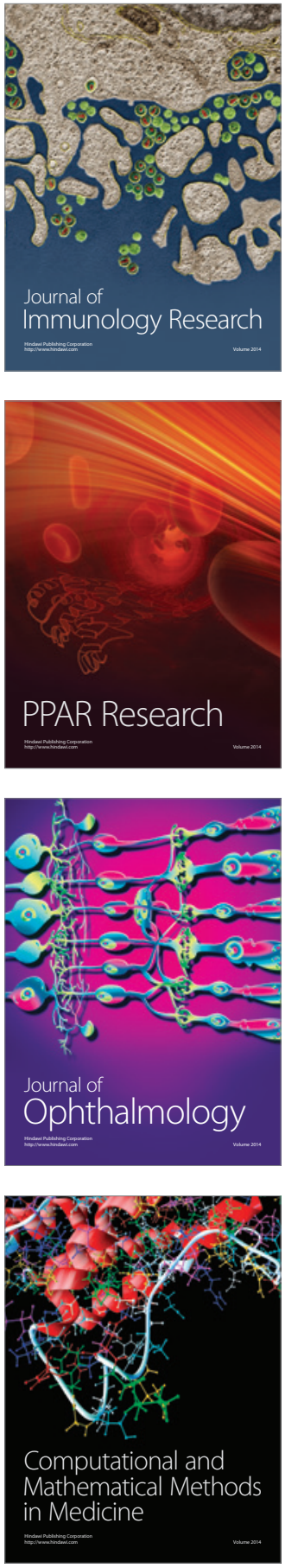

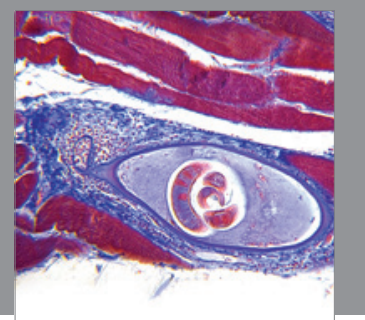

Gastroenterology

Research and Practice
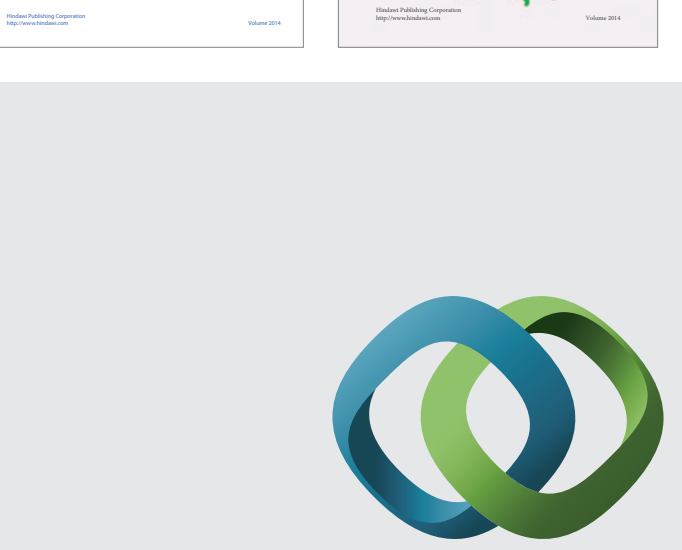

\section{Hindawi}

Submit your manuscripts at

http://www.hindawi.com
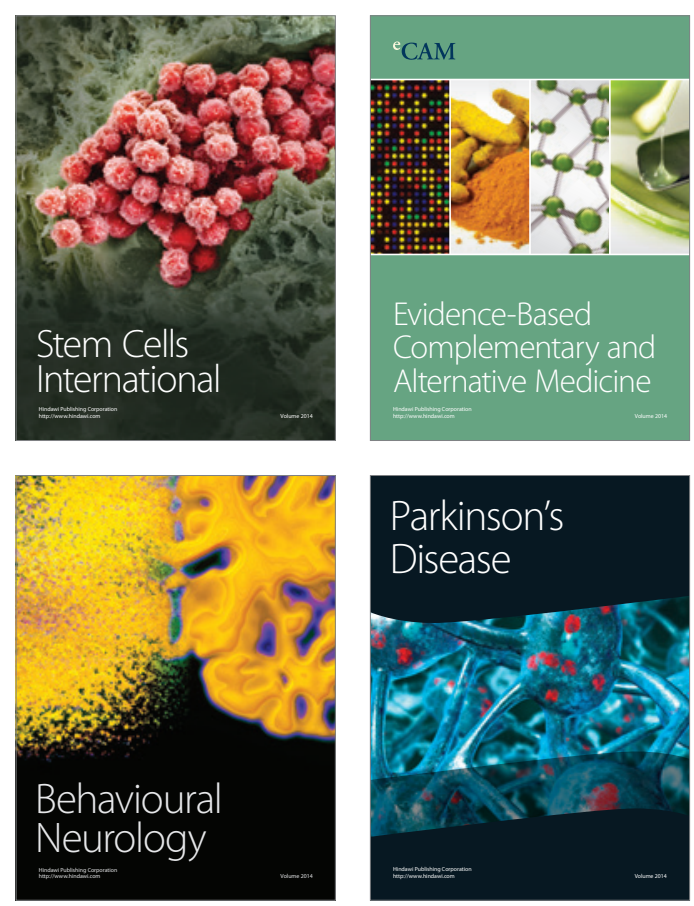

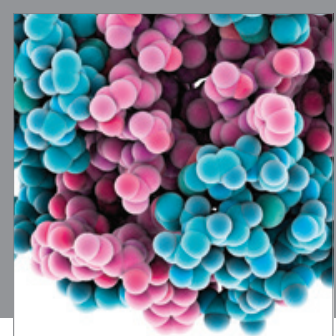

Journal of
Diabetes Research

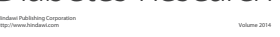

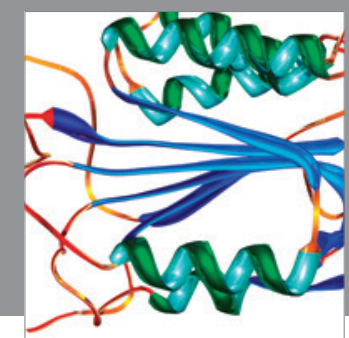

Disease Markers
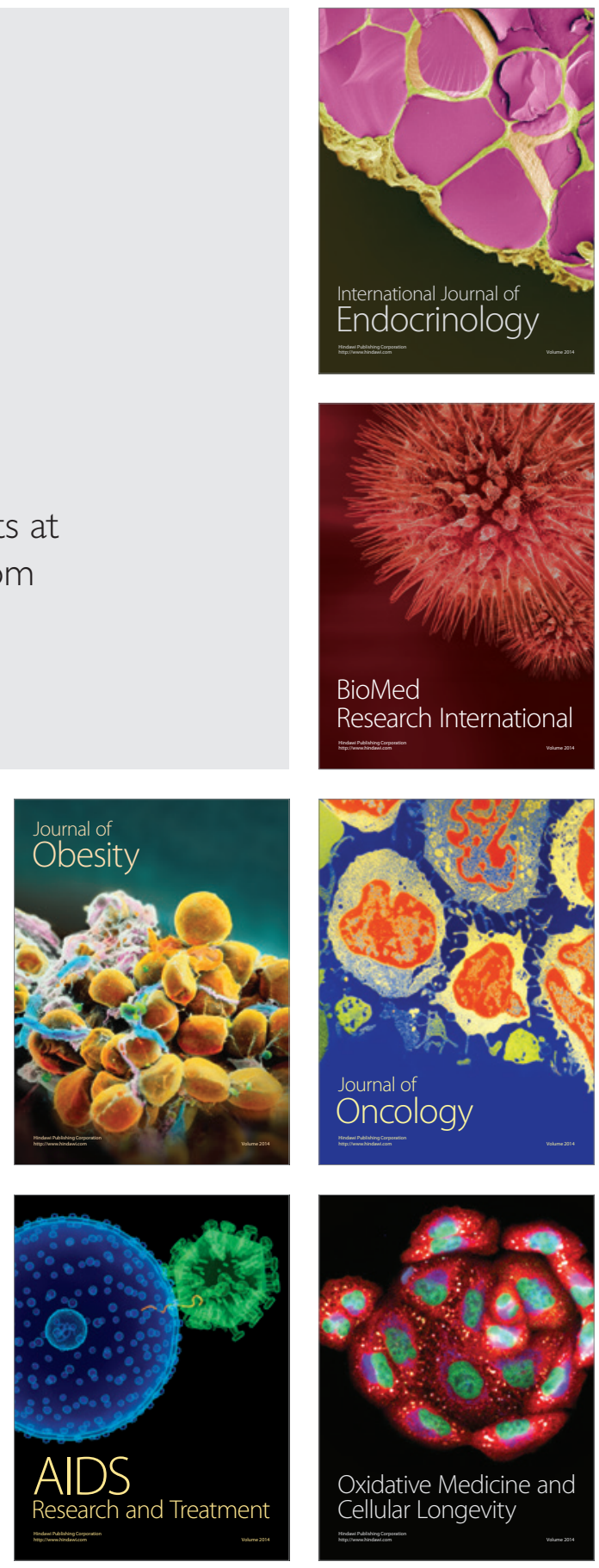